\title{
Exploring accessibility of pretreated poplar cell walls by measuring dynamics of fluorescent probes
}

\author{
Gabriel Paës", Anouck Habrant, Jordane Ossemond and Brigitte Chabbert ${ }^{*}$
}

\begin{abstract}
Background: The lignocellulosic cell wall network is resistant to enzymatic degradation due to the complex chemical and structural features. Pretreatments are thus commonly used to overcome natural recalcitrance of lignocellulose. Characterization of their impact on architecture requires combinatory approaches. However, the accessibility of the lignocellulosic cell walls still needs further insights to provide relevant information.

Results: Poplar specimens were pretreated using different conditions. Chemical, spectral, microscopic and immunolabeling analysis revealed that poplar cell walls were more altered by sodium chlorite-acetic acid and hydrothermal pretreatments but weakly modified by soaking in aqueous ammonium. In order to evaluate the accessibility of the pretreated poplar samples, two fluorescent probes (rhodamine B-isothiocyanate-dextrans of 20 and $70 \mathrm{kDa}$ ) were selected, and their mobility was measured by using the fluorescence recovery after photobleaching (FRAP) technique in a full factorial experiment. The mobility of the probes was dependent on the pretreatment type, the cell wall localization (secondary cell wall and cell corner middle lamella) and the probe size. Overall, combinatory analysis of pretreated poplar samples showed that even the partial removal of hemicellulose contributed to facilitate the accessibility to the fluorescent probes. On the contrary, nearly complete removal of lignin was detrimental to accessibility due to the possible cellulose-hemicellulose collapse.

Conclusions: Evaluation of plant cell wall accessibility through FRAP measurement brings further insights into the impact of physicochemical pretreatments on lignocellulosic samples in combination with chemical and histochemical analysis. This technique thus represents a relevant approach to better understand the effect of pretreatments on lignocellulose architecture, while considering different limitations as non-specific interactions and enzyme efficiency.
\end{abstract}

Keywords: Confocal fluorescence microscopy, Pretreatment, Poplar, Accessibility, FRAP

\section{Background}

Lignocellulosic biomass is the only renewable source of fuels, chemicals and materials that can help limiting the impact of climate changes and fossil carbon dependency [1]. Actually, enzymatic bioconversion and upgrading of lignocellulose offers an alternative strategy for the development of environmental-friendly fractionation of plant biomass. Notably, many projects are focused on the biochemical conversion of lignocellulose into fermentable sugars for the production of second generation ethanol

\footnotetext{
*Correspondence: gabriel.paes@inra.fr; brigitte.chabbert@inra.fr

*Correspondence: gabriel.paes@inra.fr; brigitte.chabbert@inra.fr
FARE laboratory, INRA, Université de Reims Champagne-Ardenne, 51100 Reims, France
}

and other biofuels $[2,3]$. However, the tight association of the plant cell wall constituents, namely cellulose, hemicellulose and lignin, creates a complex network [4] resistant to enzymatic degradation [5] thus representing an important barrier to efficient and economic bioconversion of lignocellulose [2]. Two general classes of factors limit the efficiency of enzymes: (i) structural factors, mainly related to substrate accessibility and depending on lignocellulose heterogeneous porosity [6-9]; (ii) biochemical factors regarding non-specific binding interactions of enzymes onto lignin [10-12], and all the inactivation/inhibition processes [13, 14]. Pretreatments are thus needed to overcome cell wall recalcitrance, to 
enhance enzyme accessibility and hydrolysis, by removing some components and/or disrupting the plant cell wall network [15]. As a consequence, understanding the features controlling the accessibility of enzymes into pretreated lignocellulose is an important challenge for optimizing biomass transformation processes.

Penetration and progression of enzymes into lignocellulose substrates face several limitations, from tissular to molecular scales. Chemical and structural features limiting enzyme progression in plant cell walls are complex and generally require a multiscale visualization combined to physicochemical characterization to get insights into the changes due to pretreatment [16-18]. Besides chemical and structural characterization of the whole sample, microscopic approaches such as optical microscopy, microspectrophotometry, atomic force microscopy and electron microscopy have provided critical information related to the cell wall modifications caused by both pretreatments and enzyme hydrolysis [19, 20]. Altogether these studies have shown that pretreatments induce the degradation and/or removal of the hemicellulose and lignin, and overall lignocellulose architecture and porosity can be changed drastically $[6,16,21,22]$.

Among microscopy approaches, fluorescence confocal microscopy can yield key insights into plant cell walls: mapping of plant cell walls by using plant cell wall autofluorescence [23]; identification of chemical features by immunolabeling $[24,25]$ and by measuring the binding properties of fluorescently labelled lignocelluloseactive enzymes [8]. Even spatial and temporal imaging of enzymes distribution within complex lignocellulose substrate can be carried out, indicating that cellulases preferentially bind altered plant cell walls $[26,27]$.

But there is still a lack of a method to characterize the mobility of enzymes into the complex lignocellulosic cell wall network. Usually, various porosimetry methods are applied to give access to the nano- and microarchitecture of lignocellulose [6]. But they are restricted to some physical information (pore size and morphology) and suffer from drawbacks due to sample preparation $[9,28]$. Alternatively, interesting attempts using confocal microscopy have investigated the porous structure of cellulose fibres [29]. Other biochemical techniques can provide information on the accessible surface of a specific polymer-like lignin for example [30, 31].

Mobility of various fluorescent probes has been previously evaluated by using fluorescence recovery after photobleaching (FRAP) technique, in cell wall polysaccharides [32-34] and in bioinspired plant cell wall assemblies [35-38]. In addition, fluorescent probes [39] were recently shown to provide a more comprehensive view of the nanoporosity of lignified cell walls [40]. Here, for the first time, we have used the FRAP technique to give an overview of the accessibility of lignocellulose sample, depending on the pretreatment applied, the probe size and the cell wall localization, in combination to physicochemical characterization of the pretreated samples.

\section{Results and discussion}

\section{Chemical changes induced by pretreatments}

Weight losses of 27, 17 and 30\% after HYD, AMM and CHLO pretreatments were observed, respectively. Chemical changes were evidenced by FTIR spectroscopy (Fig. 1) and wet chemistry (Table 1). Comparison of IR spectra recorded on pretreated samples vs untreated samples showed some differences depending on pretreatment. CHLO and AMM pretreated samples were the most altered as shown by the strong reduction and/or disappearance of several bands. In CHLO samples, the intensity of the bands at 1607 and $1508 \mathrm{~cm}^{-1}$ corresponding to aromatic skeletal vibration [41] was strongly reduced. In AMM samples, the bands at 1740 and $1244 \mathrm{~cm}^{-1}$ were reduced, indicating the removal of acetyl-ester of xylan and $\mathrm{C}-\mathrm{O}$ vibration from guaiacyl units [41]. Compared to CHLO and AMM, IR spectral changes in HYD samples were much lower. Only the smaller intensity of the $1740 \mathrm{~cm}^{-1}$ band corresponding to the carbonyl stretching could suggest that non-cellulosic polysaccharide might have been affected. This slight decrease was also observed in CHLO poplar. In addition, compared to the intensity of one main vibration in the region analysed $\left(1030 \mathrm{~cm}^{-1}\right)$, the $\mathrm{OH}$ plane deformation at $1201 \mathrm{~cm}^{-1}$ and the $\mathrm{C}-\mathrm{H}$ deformation peak of cellulose at $898 \mathrm{~cm}^{-1}$ were relatively increased for both CHLO and HYD samples, suggesting an increase of cellulose and/or modification in the cellulose organization. Thus, these

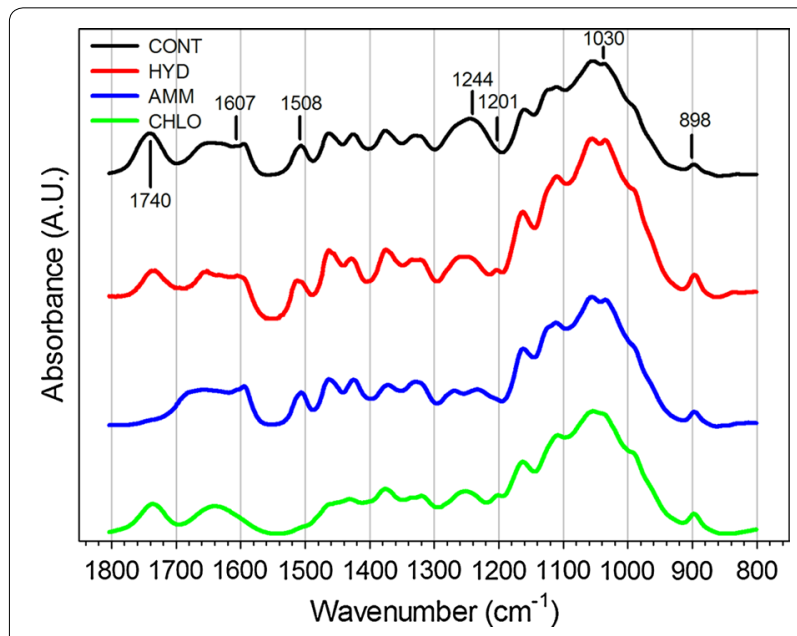

Fig. 1 FTIR spectra of untreated (CONT) and pretreated (HYD, AMM and $\mathrm{CHLO}$ ) poplar samples 
Table 1 Composition of untreated and pretreated poplar samples

\begin{tabular}{lllll}
\hline & CONT & HYD & AMM & CHLO \\
\hline Lignin content $^{\mathrm{a}}$ & $28.12 \pm 0.28$ & $31.83 \pm 0.86$ & $27.24 \pm 0.14$ & $8.54 \pm 0.37$ \\
$\mathrm{~S}+\mathrm{G}^{\mathrm{b}}$ & $1864.47 \pm 81.76$ & $1273.19 \pm 186.77$ & $1727.02 \pm 212.27$ & $180.36 \pm 19.41$ \\
$\mathrm{~S} / \mathrm{G}$ & 1.5 & 1.6 & 1.6 & 1.1 \\
Total sugars $^{\mathrm{a}}$ & $56.53 \pm 2.23$ & $59.85 \pm 2.64$ & $62.14 \pm 2.97$ & $65.85 \pm 3.33$ \\
Glucose $^{\mathrm{a}}$ & $35.95 \pm 1.40$ & $44.64 \pm 1.86$ & $40.50 \pm 1.96$ & $42.32 \pm 2.26$ \\
Xylose $^{\mathrm{a}}$ & $14.79 \pm 0.47$ & $12.25 \pm 0.61$ & $15.68 \pm 0.72$ & $17.80 \pm 0.87$ \\
Mannose $^{\mathrm{a}}$ & $2.61 \pm 0.11$ & $1.93 \pm 0.12$ & $2.97 \pm 0.14$ & $3.10 \pm 0.10$ \\
Arabinose $^{\mathrm{a}}$ & $0.35 \pm 0.01$ & $0.07 \pm 0.01$ & $0.37 \pm 0.01$ & $0.22 \pm 0.01$ \\
Galactose $^{\mathrm{a}}$ & $0.92 \pm 0.03$ & $0.25 \pm 0.01$ & $0.37 \pm 0.03$ & $0.66 \pm 0.02$ \\
Rhamnose $^{\mathrm{a}}$ & $0.38 \pm 0.01$ & $0,16 \pm 0.01$ & $1.27 \pm 0.07$ & $0.37 \pm 0.01$ \\
Galacturonic acid $^{\mathrm{a}}$ & $1.37 \pm 0.02$ & $0.50 \pm 0.03$ & $0.09 \pm 0.01$ & $1.25 \pm 0.05$ \\
Glucuronic acid $^{\mathrm{a}}$ & $0.16 \pm 0.08$ & $0.04 \pm 0.01$ & $0.13 \pm 0.01$ \\
\hline
\end{tabular}

a Lignin and sugar content expressed as percentage of dry matter

b Total yields of syringyl and guaiacyl units released by thioacidolysis expressed as $\mu \mathrm{mol} / \mathrm{g}$ lignin

pretreatments might have removed some non-cellulosic components from poplar cell walls.

In agreement with IR data, results from composition analysis indicate a strong decrease of the lignin content in CHLO samples, whereas it was slightly modified in AMM and HYD samples (Table 1). Based on the dry matter weight loss, removal of lignin represented $75 \%$ of initial lignin in CHLO samples, only 10 and 17\% in AMM and HYD, respectively. Consequently, the proportion of polysaccharides increased in pretreated samples, especially in CHLO samples which had the highest sugar content. Main changes in the proportion of hemicellulose (xylose, mannose, glucuronic acid) and pectin monosaccharides (arabinose, galactose, rhamnose, galacturonic acid) occurred in HYD samples. This result is directly related to the autohydrolysis of hemicellulose and pectins by acetic acid and other organic acids due to the cleavage of $O$-acetyl and uronic acid under liquid hot water pretreatments [42-45]. Thus HYD pretreatment removed $35 \%$ xylose, whereas less than 10\% was lost during AMM and CHLO pretreatments, as previously reported for chlorite-delignified poplar [46]. Removal in minor noncellulosic sugars such as arabinose, galactose and uronic sugars was even higher than for xylose with $70-85 \%$ loss in HYD samples. Interestingly, a smaller fraction of these minor non-cellulosic sugars was also solubilized in both CHLO samples (30-50\%) and AMM samples albeit to a much lower degree (10-20\%).

Besides these changes in cell wall composition, structural modifications of the residual lignins were also observed. Lower content of lignin monomers $(\mathrm{S}+\mathrm{G})$ was recovered after thioacidolysis of both HYD and CHLO samples, whereas AMM samples were not affected, indicating a decrease in labile aryl ether linkages (non-condensed) lignin bonds. In CHLO samples, S + G, expressed as $\mu \mathrm{mol} / \mathrm{g}$ lignin, was divided by 10 : residual lignin has become highly condensed after CHLO pretreatment. Decrease from 1.5 to 1.1 of the $\mathrm{S} / \mathrm{G}$ molar ratio further suggests a higher extractability of syringyl groups relatively to guaiacyl groups. Consistently, aryl ether linkages which are predominantly involved in syringyl-rich lignin types are less resistant to chemical degradation than guaiacyl-rich lignin [47, 48]. In HYD samples, the decrease of the non-condensed lignin proportion is in agreement with previous studies showing that during hot water treatment, lignin undergoes both depolymerization and recondensation mechanisms giving rise to pseudolignin $[20,43,49]$. Overall, IR and chemical data indicate that AMM samples were very moderately affected; hemicellulose were removed and lignin was modified in HYD samples; lignin was largely removed in CHLO samples.

\section{Histochemical changes induced by pretreatments}

UV autofluorescence in poplar cell walls is mainly due to lignin and is dependent on the lignin concentration and monolignols chemical arrangement within the cell walls [50]. Microscopic observations of cross sections of the poplar samples (mature xylem) show that the strong autofluorescence in the untreated samples (Fig. 2a) has almost disappeared in CHLO samples (Fig. 2d). HYD samples display altered UV fluorescence (Fig. 2b), whereas AMM samples (Fig. 2c) show a slight decrease of the intensity of fluorescence in the secondary walls. Change in UV autofluorescence intensity is thus consistent to previously measured lignin content.

The distribution of xylan was further investigated using the LM10 monoclonal antibody which reacts specifically with low substituted and unsubstituted $\beta$-(1-4)-linked 


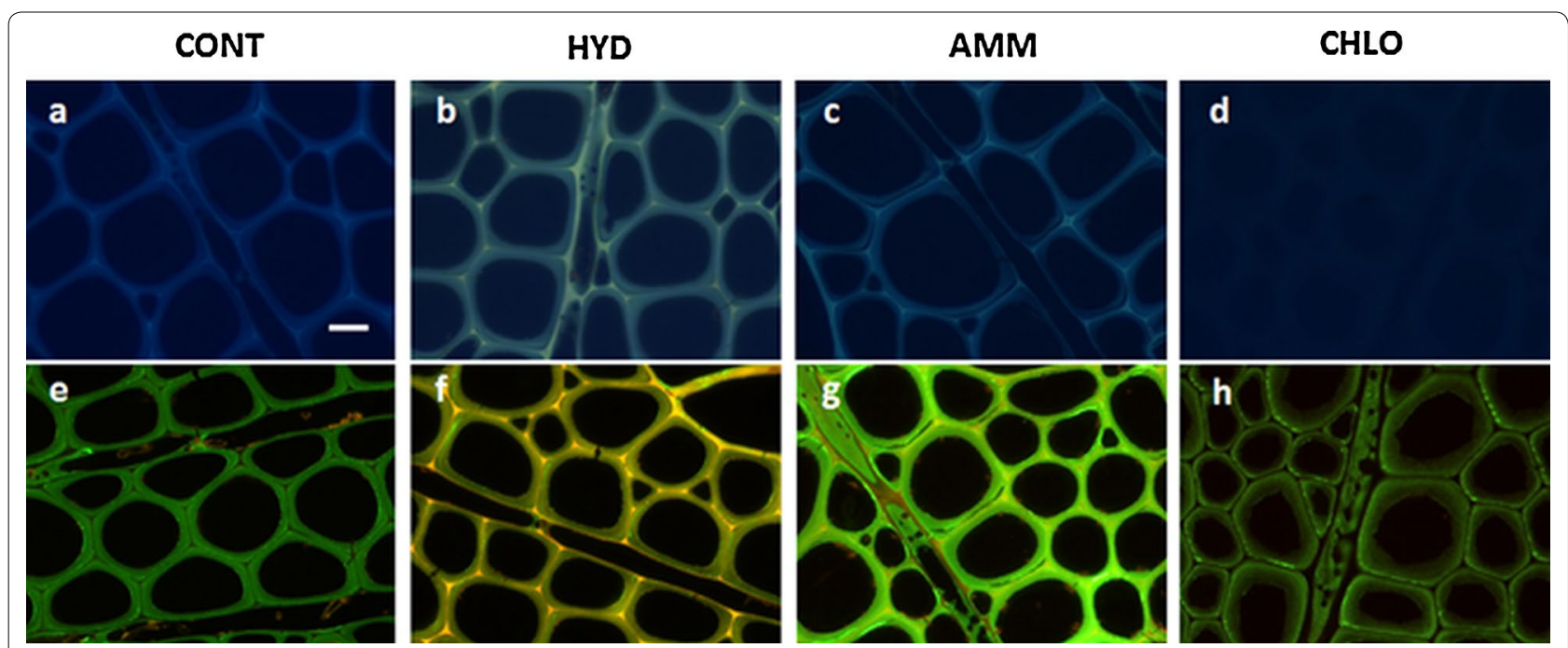

Fig. 2 UV autofluorescence (first row $\mathbf{a}-\mathbf{d}$ ) and xylan immunolabeling (second row $\mathbf{e}-\mathbf{h}$ ) of poplar sections from control sample (CONT: a, e) and pretreated samples (HYD: b, f; AMM: c, $\mathbf{g}$; CHLO: $\mathbf{d}, \mathbf{h}$ )

xylose residues as in glucuronoxylan [51]. In the untreated sample, xylan labelling was detected as green fluorescence in all the xylem cells with stronger labelling in the outer secondary cell walls but almost no labelling in the cell corner middle lamella (Fig. 2e). This distribution of xylan is similar to previous observations of poplar xylem $[25,52]$. In HYD samples, xylan labelling was faint in the secondary cell walls of the fibres (and vessels) (Fig. 2f). The labelling pattern in AMM samples was similar albeit slightly higher compared to the untreated sample (Fig. 2g). In CHLO samples, xylan immunofluorescence was decreased and was observed mainly in the outer layers of the secondary walls (Fig. 2h). Changes in the pattern of xylan immunolabeling may result from the effect of pretreatment on the number of epitopes and/or their accessibility to immunoprobe [53]. Nevertheless, observations of HYD samples suggesting xylan removal are consistent with chemical data (Table 1) and with the recent studies investigating the impact of hot water pretreatment on xylan removal from cell walls using immune-gold labelling at ultrastructural levels [25]. Overall, chemical and microscopic analyses reveal that poplar cell walls are the most altered by CHLO and HYD pretreatments.

\section{Cell wall accessibility in pretreated samples}

To complement the characterization of the pretreated samples, accessibility of poplar cell walls was evaluated at the molecular scale using some fluorescent dextranbased probes, whose mobility was determined by the FRAP technique. Indeed, such probes are considered as having few or no interaction with plant cell wall polymers
$[35,36]$ and their size and low dispersity (Table 2 ) are in the range of typical enzymes degrading plant cell walls like cellulases and xylanases $[38,54,55]$. Rhodamine B was chosen as the fluorophore appended to the dextran probe since rhodamine $B$ is excited beyond $540 \mathrm{~nm}$, which is quite far from the maximum lignin excitation that is around 350-400 nm [23]. First, experimental conditions had to be set up to determine several appropriate parameters: probe concentration, buffer $\mathrm{pH}$, poplar sample/probe incubation time and optimal microscopic parameters. Based on these trials (data not shown), incubation of the poplar sections was performed in $0.02 \mathrm{M}$ DXR20 or DXR70 probe in citrate-phosphate buffer at $\mathrm{pH} 5.0$ for $24 \mathrm{~h}$. Excitation at $543 \mathrm{~nm}$ was used for both probes (Table 2), and microscope detector gain was finely tuned so that the fluorescence measured was only emitted by the DXR probes and not by the plant cell wall autofluorescence.

In order to perform a relevant analysis, mobility experiments were organized as a full factorial experiment in which 3 parameters were varied on at least 2 levels (Fig. 3): the fluorescent probe size (20 kDa for DXR20 and $70 \mathrm{kDa}$ for DXR70), the pretreatment type (CONT, HYD,

Table 2 Main properties of fluorescent probes

\begin{tabular}{llllll}
\hline & $\begin{array}{l}\text { Theoreti- } \\
\text { cal MW } \\
(\mathbf{k D a})\end{array}$ & $\begin{array}{l}\text { Measured } \\
\mathbf{M W}(\mathbf{k D a})\end{array}$ & $\begin{array}{l}\text { Dispersity } \\
\text { index }\end{array}$ & $\begin{array}{l}\text { Measured } \\
\boldsymbol{R}_{\mathbf{H}}(\mathbf{n m})\end{array}$ & $\begin{array}{l}\text { Maximum } \\
\text { excitation/ } \\
\text { emission } \boldsymbol{\lambda} \\
\mathbf{( n m}\end{array}$ \\
\hline DXR20 & 20.0 & $20.9 \pm 0.4$ & 1.4 & 3.1 & $541 / 572$ \\
DXR70 & 70.0 & $70.0 \pm 1.2$ & 1.5 & 5.8 & $541 / 572$ \\
\hline
\end{tabular}




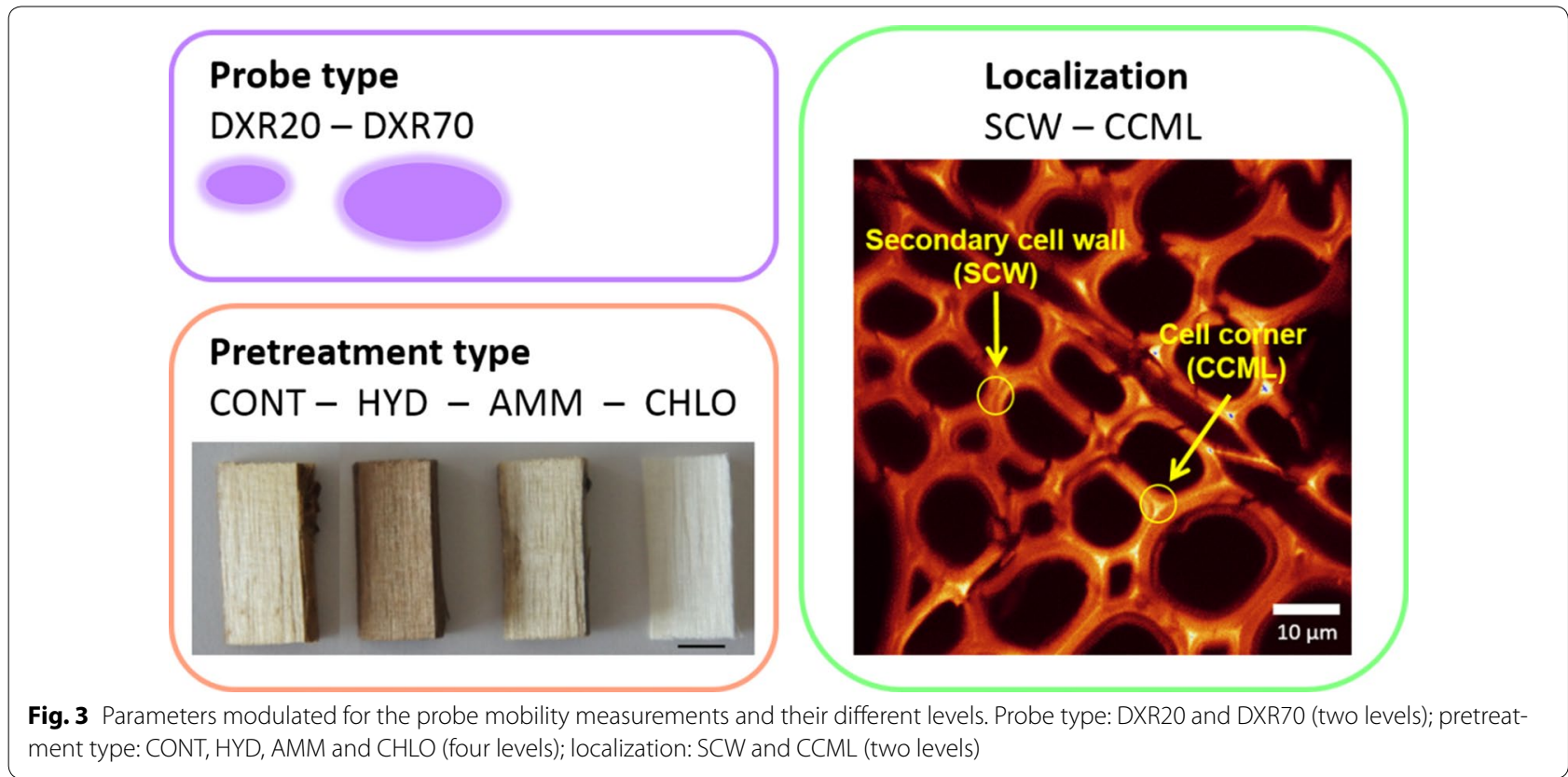

AMM and CHLO) and the cell wall localization (secondary cell walls, SCW and cell corner middle lamella, CCML). The effect of each factor was determined regarding the 2 responses obtained from the mobility measurements calculated by FRAP: the probe diffusion coefficient $D$, which is the surface the probe can move in one second and is related to the structural and chemical features of both the probe and its environment which can impact probe mobility; the probe mobile fraction $M F$, which is more directly related to the accessibility of the probe, thus to the structural features.

First, averaged values of each level for each factor were calculated for $D$ and $M F$ (Fig. 4). Regarding cell wall localization, $D$ is more than twice faster in SCW than in CCML, whereas MF in CCML (42\%) is significantly higher than in SCW (33\%) (Fig. 4). Type of pretreatment shows some contrasted results: the highest $D$ value is obtained for HYD, the lowest for CONT and AMM, while CHLO is in-between. For the MF, HYD also reaches the maximum value (nearly $50 \%$ ), CONT and AMM are just below (40\%) but CHLO is much lower (25\%) (Fig. 4b). Probe type factor indicates that DXR20 diffusion is more than twice higher than that of DXR70 but the $M F$ of the latter is higher ( $43 \%$ vs $32 \%$ ).

These results give some general trends regarding the impact of each factor, but since they are based on averaged values, they mask some discrepancies and the effect of combined factors cannot be described. So in order to provide a better interpretation of the data, only the effect of pretreatment was averaged so that the effect of probe type and localization could be compared (Fig. 5). Clearly,
$D$ is much higher for DXR20 in SCW than in CCML, while DXR70 diffusion is not influenced by the localisation (Fig. 5a). But given the high standard-deviation for DXR20-SCW, this means that there must be some large differences depending on pretreatment type. $M F$ was shown previously to be higher for DXR70 than for DXR20: this difference originates from the localization, since for both probes, $M F$ is higher in CCML than in $\mathrm{SCW}$ (Fig. 5b). In order to investigate the role of pretreatment, the effect of localization was averaged so that the effect of probe type and pretreatment could be compared (Fig. 6). Diffusion of DXR20 is higher than that of DXR70 in all pretreated samples, except for AMM samples (Fig. 6a). Importantly, diffusion in HYD samples is nearly 10-times faster for DXR20 than for DXR70. So DXR20 reaches a very high diffusion when, simultaneously, measurement is performed in SCW of HYD samples. Contrarily, $M F$ (Fig. 6b) is increased for DXR70 compared to DXR20 in all pretreatments except for CHLO.

\section{Correlation between accessibility and chemical properties of pretreated samples}

The determination of the accessibility of two different probes in two different cellular localizations from three differently pretreated poplar samples can help understand the impact of pretreatment in combination with chemical and histochemical analysis of the samples, in comparison to control samples.

In AMM samples, accessibility of the probes does not differ very much from the control on average (Fig. 4). The only striking difference refers to probe size (Fig. 6): 

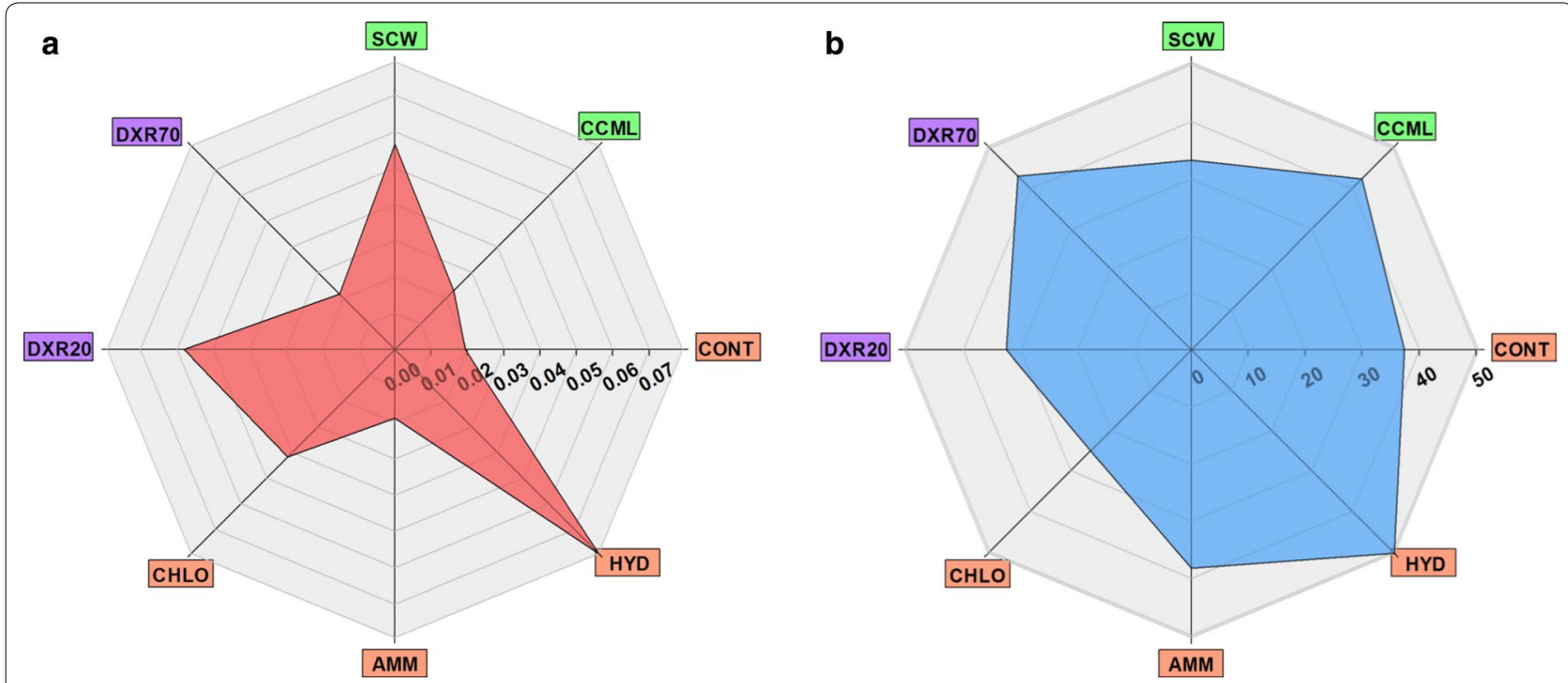

Fig. 4 a Averaged diffusion coefficient, $D$ and $\mathbf{b}$ mobile fraction, MF, values of each level for each parameter. Localization parameter (SCW and CCML) is in green, pretreatment parameter (CONT, HYD, AMM and CHLO) in orange and probe type (DXR2O and DXR70) parameter in purple. D is expressed in $\mu \mathrm{m}^{2} \mathrm{~s}^{-1}, M F$ in \%
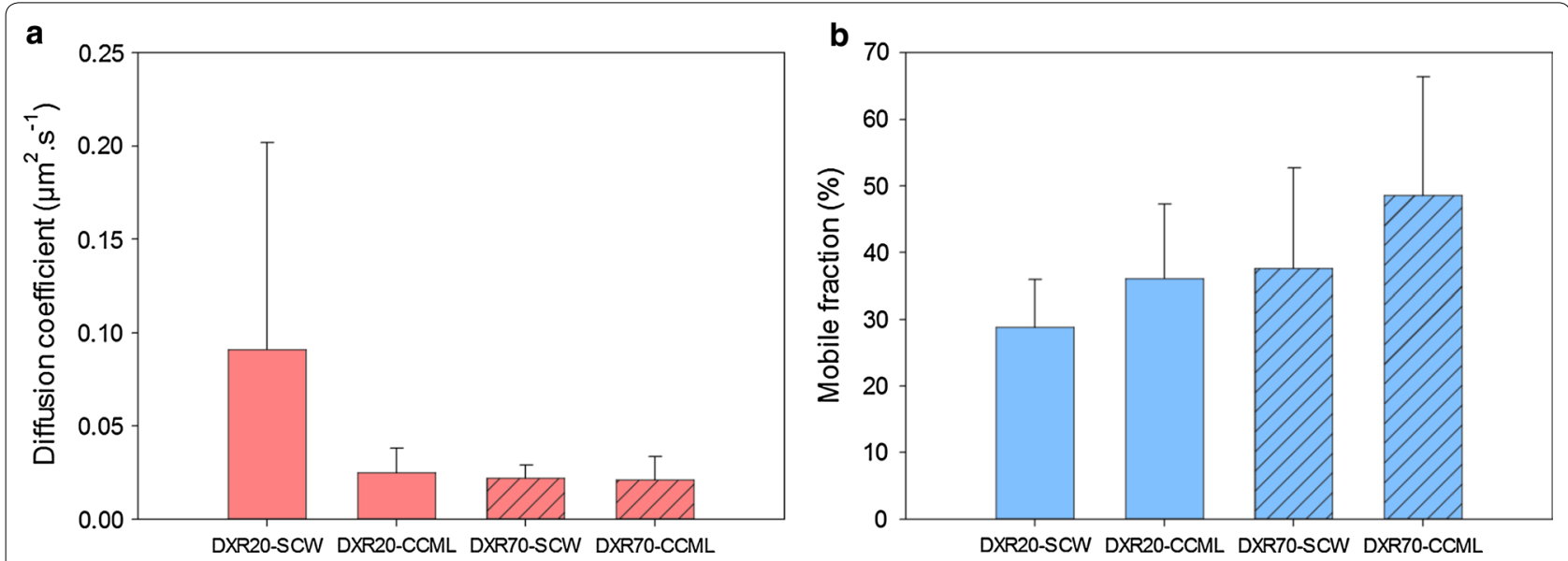

Fig. 5 a Averaged diffusion coefficient, $D$ and $\mathbf{b}$ mobile fraction, $M F$, values for the pretreatment parameter depending on probe type (DXR20 and DXR70) and localization parameters (SCW and CCML)

diffusion and mobile fractions of DXR20 are lower than those of DXR70 in both CCML and SCW, which can seem counterintuitive, because a smaller probe is expected to diffuse more slowly, in the case only structural effects are expected to control diffusion. So slowed down diffusion of DXR20 might be explained by some biochemical interactions occurring between the probe and some chemical motifs appearing in AMM samples and to be related to the loss of acetyl groups and/or to the weak modifications in hemicellulose, together with slight reduction in lignin content. These interactions would occur in the nanopores existing in the AMM samples which DXR20 can reach. For HYD samples, the large increase of accessibility (Fig. 4) is directly related to both lignin modification and to the removal of hemicellulose and of xylan in particular. For example, the lower xylan content shown by both chemical and histochemical analysis seems to facilitate the diffusion of DXR20 probe, but not that of DXR70, but $M F$ is higher for DXR70. This can be interpreted as a sieving effect in the cell wall porosity: a smaller probe can access and diffuse in smaller pores, while a twice bigger probe is excluded from these pores so it can access a larger area. 

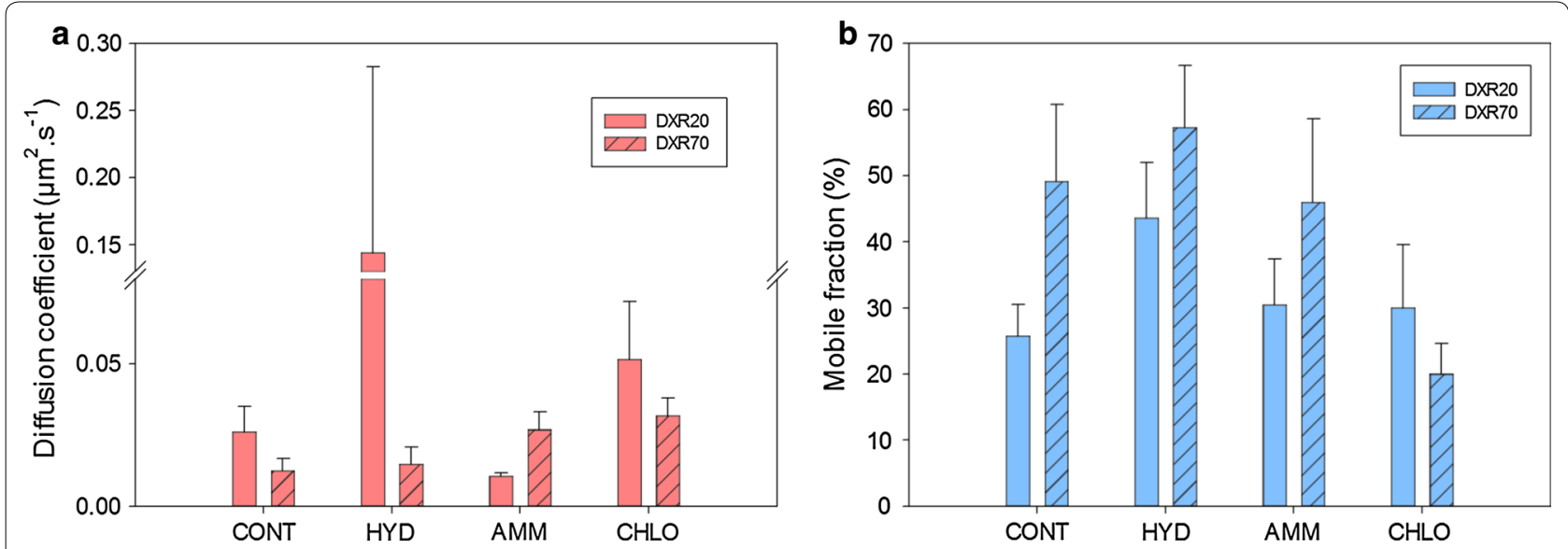

Fig. 6 a Averaged diffusion coefficient, $D$ and $\mathbf{b}$ mobile fraction, $M F$, values for the localization parameter depending on probe type (DXR20 and DXR70) and pretreatment parameters (CONT, HYD, AMM and CHLO)

This analysis thus demonstrates that HYD pretreatment affects cell wall porosity to a larger extent than chlorite delignification does. This observation is in good agreement with studies reporting that hydrothermal pretreatments increase porosity and accessible surface $[22,56]$.

Accessibility of probes in CHLO samples does not reach that measured in HYD samples, whereas lignin removal is much higher. Moreover, even if diffusion in CHLO samples is better than in CONT samples, $M F$ is the lowest among all samples analysed. CHLO pretreatment is known to have a dual effect: large removal of lignin thus drastically modifying the interactions between cellulose and hemicellulose and the formation of highly condensed lignin likely altering lignin-carbohydrate complex (LCC) bonds between hemicellulose and residual lignin. Several studies have shown that partial lignin removal rather than complete delignification combined with xylan removal would be more efficient to increase cell wall accessibility [56, 57]. Consequently, removing lignin in CHLO samples might induce rearrangement of the xylan matrix between cellulose fibrils thereby altering nanoporosity of the cell walls and probe accessibility [21].

\section{Conclusions}

Within the context of biorefinery, understanding the factors which control enzyme hydrolysis is essential. Here for the first time, the FRAP technique has been used to investigate one of these factors, the accessibility, by measuring the mobility into the lignocellulose cell walls of molecular probes whose size is representative of enzymes degrading plant materials. Overall, FRAP can report various types of information: structural accessibility of different probes, allowing to finely measure some threshold effects, in complement to porosimetry techniques; biochemical interactions by using probes interacting with cell wall chemical motifs $[38,58]$; these structural and biochemical data can be evaluated at the cellular scale, in addition to histochemical analysis which can pinpoint many different types of chemical motifs [24, 25].

Combinatory analysis of pretreated poplar samples has demonstrated that even the partial removal of hemicellulose in poplar cell walls contributes to facilitate the accessibility to dextran molecular probes. Nearly complete removal of lignin is detrimental for accessibility probably because cellulose and hemicellulose collapse. On a structural point of view, evaluation of accessibility through the measurement of accessibility by FRAP is a relevant approach to better understand and select the impact of pretreatment.

Here, only accessibility of some molecular probes was assayed. Other important parameters such as nonspecific interactions of probes should be also analysed and combined to accessibility [40]. These data might be considered in order to evaluate the correlation between structural/biochemical accessibility of enzymes and their catalytic efficiency.

\section{Methods}

\section{Fluorescent probes}

All chemicals used for analysis and pretreatment were of analytical grade. Two fluorescent probes rhodamine B-isothiocyanate-dextrans of 20 and $70 \mathrm{kDa}$ (DXR20 and DXR70, references 73,766 and T1162, respectively) were purchased from Sigma-Aldrich (Saint-Quentin-Fallavier, France). According to provider information, one rhodamine $\mathrm{B}$ molecule was bound to the dextran backbone every 100-500 glucose unit. 
Absolute molecular weight (MW), MW distribution and hydrodynamic radius $\left(R_{\mathrm{H}}\right)$ of the fluorescent probes were determined by SEC-MALS-QELS. To summarize, $150 \mu \mathrm{L}$ of each probe in $50 \mathrm{mM}$ sodium nitrate buffer was injected at $0.6 \mathrm{~mL} / \mathrm{min}$ on a KW 802.5 column equilibrated at $30{ }^{\circ} \mathrm{C}$ connected to the HPLC system (Waters 717), equipped as follows: degas, UV-visible detector (Waters 2996), multi-angle static light-scattering (MALS) detector DAWN HELEOS II (Wyatt, Santa Barbara, USA), dynamic light-scattering detector DynaPro NanoStar (Wyatt), refraction index detector (Waters 2414). Analysis of the chromatogram was performed with the ASTRA 6.1 software (Wyatt). Properties of the fluorescent probes are summarized in Table 2.

\section{Poplar sample preparation and chemical pretreatment}

Poplar wood samples were collected from 3-yearold short rotation coppice grown in experimental fields in Orléans, France. Small wood blocks (3-4 mm width $\times 2 \mathrm{~cm}$ long) were isolated from the basal region and dried overnight at $40{ }^{\circ} \mathrm{C}$ in an air-forced oven.

Three different types of pretreatment were applied in triplicates to small wood blocks. Hydrothermal treatment (HYD) was performed for $1 \mathrm{~h}$ at $170{ }^{\circ} \mathrm{C}$ at a ratio of $15 \mathrm{~mL}$ water/g poplar using mineralization reactors equipped with Teflon tubes (Parr) and an oil bath [19]. Sodium chlorite-acetic acid delignification treatment (CHLO) was performed on $1 \mathrm{~g}$ poplar using acetic acid $(0.15 \mathrm{~mL})$ and sodium chlorite $\left(1.25 \mathrm{~g} \mathrm{NaClO}_{2}\right)$ at $70{ }^{\circ} \mathrm{C}$ for $1 \mathrm{~h}$; the reaction was repeated 5 times [59]. Soaking in aqueous ammonia (AMM) treatment was carried out as previously described [60]. Poplar was soaked into 33\% aqueous ammonium (12 mL/g poplar) at room temperature for 6 days. Control samples (CONT) were also obtained after water washing at $4{ }^{\circ} \mathrm{C}(1 \mathrm{~h})$. After pretreatment, the samples were washed several times with deionized water until the $\mathrm{pH}$ of the wash was about 6.0. Then the samples were dried at $40{ }^{\circ} \mathrm{C}$ in an air-forced oven until their weight remained constant.

\section{Chemical analysis}

Control and pretreated samples were grinded to $200 \mu \mathrm{m}$ size prior to infrared spectral analysis and wet chemical degradation. Fourier transform infrared (FTIR) spectroscopy was carried out with a Nicolet 4600 instrument (Thermo Fischer Scientific, USA). KBr disks containing $2 \mathrm{mg}$ of samples were scanned 16 times from 400 to $4000 \mathrm{~cm}^{-1}$ at $4 \mathrm{~cm}^{-1}$ resolution while subtracting background spectra measured in the air. FTIR spectra were corrected for baseline and normalized on area spectra from 1900 to $800 \mathrm{~cm}^{-1}$.

Wet chemistry analysis consisted in the determination of (i) sugar monomer composition using a two-step sulfuric acid hydrolysis followed by high-performance anion-exchange chromatography (HPAEC) with 2-D-deoxyribose as internal standard, (ii) lignin content using spectrophotometric method after acetyl bromide dissolution of the lignocelluloses and (iii) monomer composition of the alkyl aryl ether lignin structures as performed by thioacidolysis as previously described [19].

\section{Wide-field fluorescence microscopy}

Poplar samples were cut into small fragments $(3 \times 3 \mathrm{~mm})$ prior to embedding into polyethylene glycol (PEG) resin or EPON resin. Samples were gradually dehydrated using ethanol series then acetone prior to epoxy resin impregnation and embedding (Epoxy Embedding Medium, EEM hardener DDSA and EEM hardener NMA, Fluka, USA). Block specimens were cut into $0.5 \mu \mathrm{m}$-thick sections using a microtome (MICROM) for UV autofluorescence observation using an Axioskop epifluorescence microscope equipped with filters at $340 \mathrm{~nm}$ for excitation and $430 \mathrm{~nm}$ for emission (Zeiss, Germany). Xylan immunolocalization was performed using LM10 and LM11 antibodies (PlantProbes, United Kingdom) which specifically bind linear xylan (LM10) and both linear and highly substituted xylan (LM11) [51]. Immunolabeling was performed as previously described [61] using Alexa Fluor 488 goat anti-rat IgG $(\mathrm{H}+\mathrm{L})$ (Life Technologies, USA) as secondary antibody prior to observations by fluorescence microscopy (Zeiss, Germany).

\section{Confocal laser scanning microscopy (CLSM) and fluorescence recovery after photobleaching (FRAP) analysis}

Small poplar fragments $(3 \times 3 \mathrm{~mm})$ were immersed in graded aqueous PEG solutions (MW $1450 \mathrm{~g} / \mathrm{mol}$ ) up to $100 \%$ PEG at $60{ }^{\circ} \mathrm{C}$. Embedding was then accomplished by cooling down PEG mixture to $25{ }^{\circ} \mathrm{C}$. Sections of $60 \mu \mathrm{m}$-thickness were obtained from PEG-embedded specimens using disposable microtome blade. PEG was removed from the sections by water washing. Sections were incubated in $50 \mathrm{mM}$ citrate-phosphate buffer at $\mathrm{pH}$ 5 containing $0.02 \mathrm{M}$ fluorescent probe DXR20 or DXR70 for $24 \mathrm{~h}$ at $20{ }^{\circ} \mathrm{C}$ in the dark, then mounted between cover glass and a \#1.5H cover-slip glass slide in phosphate buffer. FRAP experiments were performed using a Leica TCS SP2 (Mannheim, Germany) with a $63 \times$ oil immersion objective and a numerical aperture of 1.4, equipped with a $543 \mathrm{~nm}$ argon laser, in a controlled-temperature room $\left(20 \pm 2{ }^{\circ} \mathrm{C}\right)$. Images were collected using the following parameters: $1 \times$ zoom factor, $512 \times 512$ pixels size at a frequency of $400 \mathrm{~Hz}$, one acquisition, with a circular region of interest (ROI) of $4 \mu \mathrm{m}$ diameter. For FRAP experiments, prebleaching was performed with laser at $20 \%$ of its power and acquisition of five reference 
images, followed by bleaching with laser at $100 \%$, with acquisition of 40 images and finally post-bleaching (laser at $20 \%$ ) with acquisition of images until the bleached ROI intensity was constant. Calculation of the diffusion $D$ and the mobile fraction $M F$ were performed as previously described $[35,36]$.

\section{Statistical analysis}

The effect of 3 factors (probe size, pretreatment type, cell wall localisation) was evaluated using ANOVA analysis and Fisher test using Design Expert 8.0 (Stat-Ease, Minneapolis, USA).

\begin{abstract}
Abbreviations
CONT: control treatment; HYD: hydrothermal treatment; CHLO: sodium chlorite-acetic acid treatment; AMM: aqueous ammonia treatment; CCML: cell corner middle lamella; SCW: secondary cell wall; DXR20: rhodamine B-isothiocyanate dextran $20 \mathrm{kDa}$; DXR70: rhodamine B-isothiocyanate dextran $70 \mathrm{kDa}$; FRAP: fluorescence recovery after photobleaching; D: diffusion coefficient; MF: mobile fraction; G: guaiacyl; S: syringyl.
\end{abstract}

\section{Authors' contributions}

GP and BC designed the study, analysed results and wrote the manuscript. $A H$ and JO performed the experiments, analysed results and helped to revise and finalize the manuscript. All authors read and approved the final manuscript.

\section{Acknowledgements}

Authors would like to thank David Crônier for chromatography and lightscattering analysis and Antoine Portelette for chemical analysis.

\section{Competing interests}

The authors declare that they have no competing interests.

\section{Availability of data and materials}

All data generated or analysed during this study are included in this published article.

\section{Funding}

This study was funded by BPI France in the frame of Futurol project.

Received: 5 November 2016 Accepted: 6 January 2017

Published online: 14 January 2017

\section{References}

1. Menon V, Rao M. Trends in bioconversion of lignocellulose: biofuels, platform chemicals \& biorefinery concept. Prog Energy Combust. 2012;38:522-50

2. Viikari L, Vehmaanpera J, Koivula A. Lignocellulosic ethanol: from science to industry. Biomass Bioenergy. 2012;46:13-24.

3. Balan V, Chiaramonti D, Kumar S. Review of US and EU initiatives toward development, demonstration, and commercialization of lignocellulosic biofuels. Biofuels Bioprod Biorefin. 2013;7:732-59.

4. Burton RA, Gidley MJ, Fincher GB. Heterogeneity in the chemistry, structure and function of plant cell walls. Nat Chem Biol. 2010;6:724-32.

5. Zhao XB, Zhang LH, Liu DH. Biomass recalcitrance. Part I: the chemical compositions and physical structures affecting the enzymatic hydrolysis of lignocellulose. Biofuels Bioprod Biorefin. 2012;6:465-82.

6. Grethlein HE. The effect of pore-size distribution on the rate of enzymatic hydrolysis of cellulosic substrates. Nat Biotechnol. 1985;3:155-60.

7. Arantes V, Saddler JN. Access to cellulose limits the efficiency of enzymatic hydrolysis: the role of amorphogenesis. Biotechnol Biofuels. 2010;3:4.
8. Luterbacher JS, Walker LP, Moran-Mirabal JM. Observing and modeling BMCC degradation by commercial cellulase cocktails with fluorescently labeled Trichoderma reseii Cel7A through confocal microscopy. Biotechnol Bioeng. 2013;110:108-17.

9. Meng X, Ragauskas AJ. Recent advances in understanding the role of cellulose accessibility in enzymatic hydrolysis of lignocellulosic substrates. Curr Opin Biotech. 2014;27:150-8.

10. Wang ZJ, Zhu JY, Fu YJ, Qin MH, Shao ZY, Jiang JG, Yang F. Lignosulfonatemediated cellulase adsorption: enhanced enzymatic saccharification of lignocellulose through weakening nonproductive binding to lignin. Biotechnol Biofuels. 2013;6:1.

11. Gao DH, Haarmeyer C, Balan V, Whitehead TA, Dale BE, Chundawat SPS. Lignin triggers irreversible cellulase loss during pretreated lignocellulosic biomass saccharification. Biotechnol Biofuels. 2014;7:1.

12. Yu GC, Yano S, Inoue H, Inoue S, Wang JL, Endo T. Structural insights into rice straw pretreated by hot-compressed water in relation to enzymatic hydrolysis. Appl Biochem Biotech. 2014;174:2278-94.

13. Qing Q, Yang B, Wyman CE. Xylooligomers are strong inhibitors of cellulose hydrolysis by enzymes. Bioresour Technol. 2010;101:9624-30.

14. Ximenes E, Kim Y, Mosier N, Dien B, Ladisch M. Deactivation of cellulases by phenols. Enzyme Microb Tech. 2011;48:54-60.

15. Zhao XB, Zhang LH, Liu DH. Biomass recalcitrance. Part II: fundamentals of different pre-treatments to increase the enzymatic digestibility of lignocellulose. Biofuels Bioprod Biorefin. 2012;6:561-79.

16. Chundawat SPS, Donohoe BS, Sousa LD, Elder T, Agarwal UP, Lu FC, Ralph J, Himmel ME, Balan V, Dale BE. Multi-scale visualization and characterization of lignocellulosic plant cell wall deconstruction during thermochemical pretreatment. Energ Environ Sci. 2011;4:973-84.

17. Ding SY, Liu YS, Zeng YN, Himmel ME, Baker JO, Bayer EA. How does plant cell wall nanoscale architecture correlate with enzymatic digestibility? Science. 2012;338:1055-60.

18. Inouye H, Zhang Y, Yang L, Venugopalan N, Fischetti RF, Gleber SC, Vogt S, Fowle W, Makowski B, Tucker M, et al. Multiscale deconstruction of molecular architecture in corn stover. Sci Rep. 2014;4:1.

19. Belmokhtar N, Habrant A, Ferreira NL, Chabbert B. Changes in phenolics distribution after chemical pretreatment and enzymatic conversion of Miscanthus x giganteus internode. Bioenergy Res. 2013;6:506-18.

20. Ma J, Zhang X, Zhou X, Xu F. Revealing the changes in topochemical characteristics of poplar cell wall during hydrothermal pretreatment. Bioenergy Res. 2014;7:1358-68.

21. Adani F, Papa G, Schievano A, Cardinale G, D'Imporzano G, Tambone F. Nanoscale structure of the cell wall protecting cellulose from enzyme attack. Environ Sci Technol. 2011;45:1107-13.

22. Pu YQ, Hu F, Huang F, Davison BH, Ragauskas AJ. Assessing the molecular structure basis for biomass recalcitrance during dilute acid and hydrothermal pretreatments. Biotechnol Biofuels. 2013;6:1.

23. Donaldson L. Softwood and hardwood lignin fluorescence spectra of wood cell walls in different mounting media. IAWA J. 2013;34:3-19.

24. DeMartini JD, Pattathil S, Avci U, Szekalski K, Mazumder K, Hahn MG, Wyman CE. Application of monoclonal antibodies to investigate plant cell wall deconstruction for biofuels production. Energy Environ Sci. 2011:4:4332-9.

25. Blumentritt M, Gardner DJ, Cole BJW, Shaler SM. Influence of hot-water extraction on ultrastructure and distribution of glucomannans and xylans in poplar xylem as detected by gold immunolabeling. Holzforschung. 2016;70:243-52.

26. Donohoe BS, Selig MJ, Viamajala S, Vinzant TB, Adney WS, Himmel ME. Detecting cellulase penetration into corn stover cell walls by immunoelectron microscopy. Biotechnol Bioeng. 2009;103:480-9.

27. Luterbacher JS, Moran-Mirabal JM, Burkholder EW, Walker LP. Modeling enzymatic hydrolysis of lignocellulosic substrates using confocal fluorescence microscopy l: filter paper cellulose. Biotechnol Bioeng. 2015;112:21-31.

28. Chesson A, Gardner PT, Wood TJ. Cell wall porosity and available surface area of wheat straw and wheat grain fractions. J Sci Food Agric. 1997:75:289-95.

29. Yang D, Moran-Mirabal JM, Parlange JY, Walker LP. Investigation of the porous structure of cellulosic substrates through confocal laser scanning microscopy. Biotechnol Bioeng. 2013;1 10:2836-45.

30. Vaidya AA, Newman RH, Campion SH, Suckling ID. Strength of adsorption of polyethylene glycol on pretreated Pinus radiata wood and 
consequences for enzymatic saccharification. Biomass Bioenerg. 2014;70:339-46.

31. Sipponen MH, Pihlajaniemi V, Littunen K, Pastinen O, Laakso S. Determination of surface-accessible acidic hydroxyls and surface area of lignin by cationic dye adsorption. Bioresour Technol. 2014;169:80-7.

32. Cuyvers S, Hendrix J, Dornez E, Engelborghs Y, Delcour JA, Courtin CM. Both substrate hydrolysis and secondary substrate binding determine xylanase mobility as assessed by FRAP. J Phys Chem B. 2011;115:4810-7.

33. Dornez E, Cuyvers S, Holopainen U, Nordlund E, Poutanen K, Delcour JA Courtin CM. Inactive fluorescently labeled xylanase as a novel probe for microscopic analysis of arabinoxylan containing cereal cell walls. J Agric Food Chem. 2011;59:6369-75.

34. Moran-Mirabal JM. The study of cell wall structure and cellulosecellulase interactions through fluorescence microscopy. Cellulose. 2013;20:2291-309.

35. Paës G, Chabbert B. Characterization of arabinoxylan/cellulose nanocrystals gels to investigate fluorescent probes mobility in bioinspired models of plant secondary cell wall. Biomacromolecules. 2012;13:206-14.

36. Paës G, Burr S, Saab MB, Molinari M, Aguié-Béghin V, Chabbert B. Modeling progression of fluorescent probes in bioinspired lignocellulosic assemblies. Biomacromolecules. 2013;14:2196-205.

37. Lopez-Sanchez P, Schuster E, Wang D, Gidley MJ, Strom A. Diffusion of macromolecules in self-assembled cellulose/hemicellulose hydrogels. Soft Matter. 2015;11:4002-10.

38. Fong $\mathrm{M}$, Berrin JG, Paës $\mathrm{G}$. Investigation of the binding properties of a multi-modular GH45 cellulase using bioinspired model assemblies. Biotechnol Biofuels. 2016;9:1.

39. Paës G. Fluorescent probes for exploring plant cell wall deconstruction: a review. Molecules. 2014:19:9380-402.

40. Donaldson LA, Kroese HW, Hill SJ, Franich RA. Detection of wood cell wall porosity using small carbohydrate molecules and confocal fluorescence microscopy. J Microsc. 2015;259:228-36.

41. Schwanninger $M$, Rodriques JC, Pereira $H$, Hinterstoisser B. Effects of short-time vibratory ball milling on the shape of FT-IR spectra of wood and cellulose. Vibr Spectrosc. 2004;36:23-40.

42. Mosier N, Wyman C, Dale B, Elander R, Lee YY, Holtzapple M, Ladisch M. Features of promising technologies for pretreatment of lignocellulosic biomass. Bioresour Technol. 2005;96:673-86.

43. Assor C, Placet V, Chabbert B, Habrant A, Lapierre C, Pollet B, Perré P. Concomitant changes in viscoelastic properties and amorphous polymers during the hydrothermal treatment of hardwood and softwood. J Agric Food Chem. 2009;57:6830-7.

44. Behera S, Arora R, Nandhagopal N, Kumar S. Importance of chemical pretreatment for bioconversion of lignocellulosic biomass. Renew Sust Energ Rev. 2014;36:91-106.

45. Trajano HL, Pattathil S, Tomkins BA, Tschaplinski TJ, Hahn MG, Van Berkel GJ, Wyman CE. Xylan hydrolysis in Populus trichocarpa $\times$ P. deltoides and model substrates during hydrothermal pretreatment. Bioresour Technol. 2015;179:202-10.
46. Kumar R, Hu F, Hubbell CA, Ragauskas AJ, Wyman CE. Comparison of laboratory delignification methods, their selectivity, and impacts on physiochemical characteristics of cellulosic biomass. Bioresour Technol. 2013;130:372-81.

47. Ralph J, Brunow G, Boerjan W. Lignins. Encyclopedia of life sciences. Hoboken: Wiley; 2007.

48. Mottiar Y, Vanholme R, Boerjan W, Ralph J, Mansfield SD. Designer lignins: harnessing the plasticity of lignification. Curr Opin Biotech. 2016:37:190-200

49. Trajano HL, Engle NL, Foston M, Ragauskas AJ, Tschaplinski TJ, Wyman CE. The fate of lignin during hydrothermal pretreatment. Biotechnol Biofuels. 2013;6:1.

50. Donaldson L, Hague J, Snell R. Lignin distribution in coppice poplar, linseed and wheat straw. Holzforschung. 2001;55:379-85.

51. McCartney L, Marcus SE, Knox JP. Monoclonal antibodies to plant cell wall xylans and arabinoxylans. J Histochem Cytochem. 2005;53:543-6.

52. Kim JS, Sandquist D, Sundberg B, Daniel G. Spatial and temporal variability of xylan distribution in differentiating secondary xylem of hybrid aspen. Planta. 2012;235:1315-30.

53. Xue J, Bosch M, Knox JP. Heterogeneity and glycan masking of cell wall microstructures in the stems of Miscanthus $\times$ giganteus, and its parents M. sinensis and M. sacchariflorus. PLOS ONE. 2013:8:e82114.

54. Kozak M. Solution scattering studies of conformation stability of xylanase XYNII from Trichoderma longibrachiatum. Biopolymers. 2006;83:95-102.

55. Luterbacher JS, Parlange JY, Walker LP. A pore-hindered diffusion and reaction model can help explain the importance of pore size distribution in enzymatic hydrolysis of biomass. Biotechnol Bioeng. 2013;110:127-36.

56. Meng XZ, Wells T, Sun QN, Huang F, Ragauskas A. Insights into the effect of dilute acid, hot water or alkaline pretreatment on the cellulose accessible surface area and the overall porosity of Populus. Green Chem. 2015:17:4239-46.

57. Ishizawa Cl, Jeoh T, Adney WS, Himmel ME, Johnson DK, Davis MF. Can delignification decrease cellulose digestibility in acid pretreated corn stover? Cellulose. 2009;16:677-86.

58. Moran-Mirabal JM, Bolewski JC, Walker LP. Thermobifida fusca cellulases exhibit limited surface diffusion on bacterial micro-crystalline cellulose. Biotechnol Bioeng. 2013;110:47-56.

59. Wise LE, Murphy M, D'Addieco AA. Chlorite holocellulose, its fractionation and bearing on summative wood analysis and on studies on the hemicelluloses. Paper Trade J. 1946;122:11-9.

60. Rémond C, Aubry N, Cronier D, Noel S, Martel F, Roge B, Rakotoarivonina H, Debeire P, Chabbert B. Combination of ammonia and xylanase pretreatments: impact on enzymatic xylan and cellulose recovery from wheat straw. Bioresour Technol. 2010:101:6712-7.

61. Chantreau M, Portelette A, Dauwe R, Kiyoto S, Crônier D, Morreel K, Arribat S, Neutelings G, Chabi M, Boerjan W, et al. Ectopic lignification in the flax lignified bast fiber1 mutant stem is associated with tissue-specific modifications in gene expression and cell wall composition. Plant Cell. 2014:26:4462-82.

\section{Submit your next manuscript to BioMed Central and we will help you at every step:}

- We accept pre-submission inquiries

- Our selector tool helps you to find the most relevant journal

- We provide round the clock customer support

- Convenient online submission

- Thorough peer review

- Inclusion in PubMed and all major indexing services

- Maximum visibility for your research

Submit your manuscript at www.biomedcentral com/submit
BioMed Central 